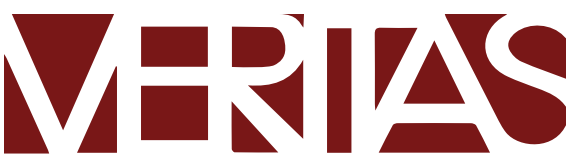

$\begin{array}{lllllllllll}P & O & R & T & O & A & L & E & G & R & E\end{array}$

http://dx.doi.org/10.15448/1984-6746.2019.3.32795

\title{
OS USOS DO SENSO COMUM NA FILOSOFIA DE THOMAS REID
}

\section{The uses of the common sense in Thomas Reid's philosophy Los usos del sentido común en la filosofía de Thomas Reid}

\author{
Vinícius França Freitas '
}

Universidade Federal de Minas Gerais, Belo Horizonte, MG, Brasil.

\section{Resumo}

Este artigo empreende a discussão dos papéis filosóficos do senso comum no pensamento de Thomas Reid. Argumento que, para o filósofo, não existe apenas uma forma de se apelar ao senso comum no campo teórico relativo à descoberta da verdade e à fundamentação do conhecimento. De acordo com minha leitura, Reid faz ao menos três usos distintos do senso comum: (1) o uso fundacional, no qual o senso comum é tomado como o fundamento sobre o qual o conhecimento deve ser erigido; (2) o uso metodológico, no qual o senso comum surge como fonte de pressupostos metodológicos de investigações filosóficas; (3) o uso instrumental, no qual o senso comum, a partir da emoção do ridículo, é utilizado como ponto de apoio para se refutar princípios e conclusões filosóficas.

Palavras-chave: Thomas Reid. Senso comum. Fundamento. Método. Refutação.

\section{Abstract}

This paper aims to discuss the philosophical roles of common sense in Thomas Reid's thought. I argue that there is not only one way of appealing to common sense in at-

1 Doutor em Filosofia pela Universidade Federal de Minas Gerais (UFMG) e pela Université Paris 1 Panthéon-Sorbonne (2017). ORCID: http://orcid.org/oooo-0002-8304-4732. E-mail: ffvinicius@yahoo.com.br 
tempt of discovering truth and allowing knowledge. According to my understanding, Reid makes at least three distinct uses of common sense: (1) the foundational use, in which common sense is taken as the foundation upon which knowledge must be built; (2) the methodological use, in which common sense arises as a source of methodological presuppositions of philosophical investigations; (3) the instrumental use, in which common sense, in the light of the emotion of ridicule, is used as an instrument to refute philosophical principles and conclusions.

Keywords: Thomas Reid. Common sense. Foundation. Method. Refutation.

\section{Resumen}

Este artículo toma la discusión de los papeles filosóficos del sentido común en el pensamiento de Thomas Reid. Argumento que, para el filósofo, no hay sólo una manera de apelar al sentido común en el campo teórico sobre el descubrimiento de la verdad y la justificación del conocimiento. Según mi lectura, Reid hace al menos tres usos distintos del sentido común: (1) el uso fundacional, en que sentido común se toma como la base sobre la cual debe construirse el conocimiento; (2) el uso metodologico, en el cual el sentudo común emerge como una fuente de hipótesis metodológicas de Investigaciones filosóficas; (3) uso de instrumental, en que sentudo común, a partir de la emoción del ridículo, se utiliza como punto de apoyo para refutar y principios y las conclusiones filosóficas.

Palabras clave: Thomas Reid. Sentido común. Fundación. Método. Refutación.

\section{Introdução}

Ao pensar o papel do senso comum no tocante à vida humana, Thomas Reid (1710-1796) concebe-lhe ao menos dois fins. Por um lado, o senso comum possui um uso prático, relativo ao domínio das ações humanas: 0 senso comum orienta-nos na conduta de nossas vidas política e moral ${ }^{2}$. Por outro lado, o senso comum possui um uso filosófico, relativo ao domínio das possibilidades de descoberta da verdade e de fundamentação do conhecimento humano. Reid, em seu estudo da história da filosofia moderna, nota que as conclusões absurdas a que chegaram os filósofos dos séculos

\footnotetext{
2 Reid afirma: "existe um certo grau dele [senso comum] que é necessário para sermos sujeitos à lei e ao governo, sermos capazes de manejar nossos próprios negócios e sermos responsáveis por nossas condutas em relação aos outros. Isto é chamado senso comum, porque é comum a todos os homens com quem realizamos negócios ou chamamos para responder por suas condutas" (REID, 2002, p. 426, tradução nossa).
} 
XVII e XVIII ${ }^{3}$ devem ser compreendidas como resultado da tentativa dos filósofos de irem além das fronteiras estabelecidas pelo senso comum:

Pode ser observado que os defeitos e manchas na filosofia da mente recebida, que mais a expõem ao desprezo e ao ridículo dos homens razoáveis, devem-se principalmente a isto, que os adeptos dessa filosofia, a partir de um preconceito natural em favor desta, esforçaram-se para estender sua jurisdição para além de seus limites exatos [...] (REID, 1997, p. 19, tradução nossa4).

A condição miserável da filosofia - especialmente, segundo Reid, quando comparada ao sucesso da matemática e ao progresso da filosofia natural - é devida ao erro de tentar ultrapassar as fronteiras indicadas pelo senso comum, de estender a jurisdição da filosofia além das fronteiras apontadas pelos princípios da constituição original da mente:

Os filósofos do último século, dentre aqueles que mencionei [referindo-se a Descartes, Malebranche e Locke], não trataram de preservar a união e a subordinação tão cuidadosamente quanto exigiam o interesse e a honra da filosofia. Contudo, os filósofos do presente [referindo-se a Berkeley e Hume] travam uma guerra aberta com o Senso Comum, na esperança de conquistá-lo completamente pelas sutilezas da Filosofia, uma tentativa não menos audaciosa e vã do que aquela dos gigantes de destronar Júpiter (REID, 1997, p. 19, tradução nossa5).

\footnotetext{
3 Reid pensa, em particular, nas conclusões de George Berkeley - que, a seu ver, nega a existência dos objetos do mundo externo - e David Hume - que, a seu ver, nega a existência de relações causais na natureza, a existência dos objetos do mundo externo e a existência da própria mente.

4 Do original: It may be observed, that the defects and blemishes in the received philosophy of the mind, which have most exposed it to the contempt and ridicule of sensible men, have chiefly been owing to this: that the votaries of this Philosophy, from a natural prejudice in her favour, have endeavoured to extend her jurisdiction beyond its just limits.

5 Do original: The philosophers of the last age, whom I have mentioned, did not attend to preserving the union and subordination so carefully as the honour and interest of philosophy required: but those of the present have waged 'open war' with Common Sense, and hope to make a complete conquest of it by the subtilties of Philosophy; an attempt no less audacious and vain, than that of the giants to dethrone almighty Jove.
} 
Neste contexto de uma filosofia repleta de opiniões absurdas, Reid entende o seu projeto filosófico como uma tentativa de reconciliar filosofia e senso comum. Eis a metáfora que explica a relação entre a filosofia da mente e o senso comum:

Nesta disputa desigual entre Senso Comum e Filosofia, esta última sempre acabará em desonra e prejuízo, de modo que ela nunca prosperará a menos que esta rivalidade seja posta de lado, que estas usurpações sejam abandonadas e sua amizade cordial seja restaurada. Pois, em realidade, o Senso Comum não possui nada da Filosofia, nem precisa de seu auxílio. Por outro lado, no entanto, a Filosofia (se me é permitido mudar a metáfora) não possui outra raiz senão os princípios do Senso Comum. Ela cresce deles e deles extrai seu alimento. Separada de suas raízes, sua honra murcha, seca-se sua seiva, ela morre e apodrece (REID, 1997, p. 19, tradução nossa ${ }^{6}$ ).

A proposta deste artigo deve ser entendida à luz dessa intenção de Reid de conciliar filosofia e senso comum. Pretende-se explicar os usos que o filósofo faz do senso comum, os modos de se recorrer ao senso comum em questões que extrapolam o fim prático da vida humana. Argumento que não existe, na filosofia reidiana, apenas uma maneira de se apelar ao senso comum. A meu ver, o filósofo concebe-lhe ao menos três usos: (1) o uso fundacional, no qual o senso comum aparece como o fundamento sobre o qual o conhecimento humano deve ser erigido; (2) o uso metodológico, no qual o senso comum aparece como fonte de pressupostos metodológicos de investigação em certos campos do

\footnotetext{
6 Do original: In this unequal contest betwixt Common Sense and Philosophy, the latter will always come off both with dishonour and loss; nor can she ever thrive till this rivalship is dropt, these incroachments given up, and a cordial friendiship restored: for, in reality, Common Sense holds nothing of Philosophy, nor needs her aid. But, on the other hand, Philosophy (if I may be permitted to change the metaphor) has no other root but the principles of Common Sense; it grows out of them, and draws its nourishment from them: severed from this root, its honours wither, its sap is dried up, it dies and rots.
} 
conhecimento; (3) o uso instrumental, no qual o senso comum, a partir da emoção do ridículo, aparece como ponto de apoio para se refutar princípios e conclusões filosóficas que o contradizem.

Antes de prosseguir, peço licença para apresentar um esclarecimento sobre o que, a meu ver, Reid entende por 'senso comum'. O filósofo não foi deveras claro a esse respeito. Sinal disto é a inexistência de consenso, do ponto de vista da história da filosofia ${ }^{7}$ e da literatura secundária sobre o pensamento reidiano ${ }^{8}$, a respeito do que ele tem em vista por esta noção. Para os propósitos do artigo, limito-me a afirmar que, a meu ver, o senso co-

7 Por exemplo, no prefácio dos Prolegômenos a Toda Metafísica Futura (1988), Kant critica veementemente o apelo dos filósofos ao senso comum: "é, de fato, um grande presente do céu possuir um senso recto (ou, como se chamou recentemente, um simples bom senso). Mas deve maniferstar-se pelos actos, pelo que se pensa e se diz de reflectido e de racional, não recorrendo a ele como a um oráculo, quando nada de inteligente se sabe aduzir para sua justificação. Quando o discernimento e a ciência declinam, apelar então, e não antes, para o senso comum, eis uma das subtis invenções dos tempos novos; o mais insípido tagarela pode assim arrostar confiadamente o cérebro mais sólido e resistir-lhe. Mas, enquanto houver ainda um pequeno resto de discernimento, tomar-se-á o cuidado de não recorrer a este expediente. E, visto de mais perto, este apelo não é mais do que uma referência ao juízo da multidão; aprovação de que corará o filósofo, mas o engenho popular triunfa e é arrogante" (KANT, 1988, p. 16). Kant identifica o apelo destes filósofos ao senso comum como um apelo ao juízo da multidão, à opinião do vulgo. $O$ que importa para Reid, no que diz respeito às crenças partilhadas por grande parte da humanidade, é o fato de que estas opiniões são resultados da própria constituição original da mente humana. A opinião dos seres humanos, mantidas ao longo dos séculos, é reflexo dos princípios originais da constituição da mente que determina as noções e crenças comuns.

8 James Sommerville (1987) discute algumas das dificuldades interpretativas de se compreender o que Reid tem em vista ao se referir ao senso comum. Nicholas Wolterstorff (2001) considera esse o aspecto mais confuso da filosofia reidiana: "deve ser concedido que a discussão de Reid do Senso Comum confunde. E não apenas confunde, mas é confusa: ela tanto nos confunde quanto revela confusão em Reid. Julgo ser, na verdade, a parte mais confusa da filosofia de Reid. Ironicamente, esta deve ser também a parte mais famosa" (SOMMERVILLE, 2001, p. 218, tradução nossa). Louise Marcil-Lacoste (1982) aponta alguns dos significados apresentados pelos comentadores da filosofia reidiana à noção de senso comum: (1) o senso comum interpretado como como uma faculdade, identificada, às vezes, com a sagacidade prática, a razão intuitiva, a inteligência mediana, o intelecto bem balanceado; (2) o senso comum interpretado como um conjunto de princípios, identificados, às vezes, com as crenças ordinárias, verdades autoevidentes, conclusões populares, julgamentos intuitivos, leis da mente; (3) o senso comum interpretado como uma doutrina ou um conjunto de pressuposições relativas à fonte de certeza, evidência ou verdade, identificado, às vezes, com princípios de dedução ou condições necessárias no exercício dos poderes racionais (1982, p. 74). Ronald E. Beanblossom também aponta três sentidos para o termo senso comum na filosofia de Reid: (a) um poder da mente comum a todos os seres humanos; (b) o corpo de crenças geralmente aceitas como verdadeiras; (c) o princípio de autoevidência que permeia estas crenças comumente mantidas (1983 p. XXVI-XXVII). 
mum em Reid não é senão um conjunto de princípios originais da mente que determinam o ser humano no tocante a suas noções, crenças e inclinações e também os próprios juízos e crenças que são devidos a estes princípios. Por exemplo: a constituição da mente possui certos princípios originais que produzem as noções e crenças acerca da existência do mundo9 ${ }^{9}$, do passado ${ }^{10}$ e das relações causais entre os objetos" ${ }^{11}$. Mais: o senso comum é composto das crenças que são resultados das operações destes princípios originais, como, por exemplo, as crenças na existência das operações da mente, na existência do passado ou na existência presente dos objetos percebidos pelos sentidos. Como aponta a seguinte passagem acerca desse ponto:

Estes juízos naturais e originais são portanto uma parte daquele mobiliário que a natureza forneceu ao entendimento humano [...] Eles são úteis enquanto nos governam nos interesses comuns da vida, onde nossa faculdade de raciocinar nos deixa na escuridão. Eles são parte de nossa constituição, e todas as descobertas de nossa razão são apoiadas sobre eles. Eles formam o que é chamado de 'senso comum da humanidade', e o que é manifestamente contrário a algum destes primeiros princípios, é o que é chamado 'absurdo' (REID, 1997, p. 215tradução nossa' ${ }^{12}$ ).

\footnotetext{
9 Reid diz: "sensação e memória portanto são operações mentais simples, originais e perfeitamente distintas, e ambas são 'princípios originais de crença'” (REID, 1997, p. 29, grifo e tradução nossos).

10 Ver nota anterior.

1 Reid diz: "Ele [o Autor da natureza] implantou na mente humana um 'princípio original' por meio do qual acreditamos e esperamos a continuidade do curso da natureza, e a continuidade destas conexões que foram observadas no passado. É por este princípio geral de nossa natureza que, quando duas coisas encontram-se conectadas no passado, o surgimento de uma 'produz a crença' na outra" (REID, 1997, p. 197, grifo e tradução nossos).

12 Do original: Such original and natural judgments are therefore a part of that furniture which nature hath given to the human understanding [...] They serve to direct us in the common affairs of life, where our reasoning faculty would leave us in the dark. They are a part of our constitution, and all the discoveries of reason are grounded upon them. They make up what is called 'the common sense of mankind'; and what is manifestly contrary to any of those first principles, is what we call "absurd".
} 
Acredito que esta concisa explicação seja suficiente para os propósitos deste artigo. A partir dos textos de "Uma investigação sobre a mente humana a partir dos princípios do senso comum" (1997), dos "Ensaios sobre os poderes intelectuais do homem" (2002) e dos "Ensaios sobre os poderes ativos do homem" (2010), proponho explicar os usos filosóficos feitos por Reid do senso comum, este conjunto de princípios originais da mente que determinam o ser humano no tocante a suas noções, crenças e inclinações e também os próprios juízos e crenças que são devidos a esses princípios ${ }^{13}$.

\title{
10 uso fundacional do senso comum
}

De acordo com Reid, os filósofos devem direcionar sua atenção ao senso comum e reconhecê-lo como ponto de apoio dos raciocínios filosóficos. Ele é o verdadeiro fundamento sobre o qual a filosofia e muitos outros ramos do saber devem ser construídos:

\begin{abstract}
Todo o conhecimento e toda ciência devem ser construídos sobre princípios que são autoevidentes. De tais princípios, todo homem que tem senso comum é um juiz competente, quando ele os concebe distintamente. É uma consequência que disputas frequentemente terminem em apelo ao senso comum (REID, 2002, p. 426, tradução nossa ${ }^{14}$ ).
\end{abstract}

Os princípios autoevidentes de que fala o filósofo são os princípios primeiros do senso comum, as crenças partilhadas por grande parte da humanidade e que são devidas às operações das faculdades mentais, como, por exemplo, as faculdades da consciência, memória, percepção

\footnotetext{
13 Todas as passagens citadas das obras reidianas são de tradução própria.

14 Do original: All knowledge, and all science, must be built upon principles that are self-evident; and of such principles, every man who has common sense is a competent judge, when he conceives them distinctly. Hence it is, that disputes very often terminate in an appeal to common sense.
} 
e consciência moral. Para Reid, essas crenças devidas a essas faculdades devem ser assumidas como princípios de conhecimento:

Reconheço que se fossemos nos manter sobre aqueles juízos da natureza [as crenças devidas às operações das faculdades da mente] de que falamos agora, sem construir outros sobre eles, eles não autorizariam a denominação de seres razoáveis. Contudo, eles não devem ser desprezados, pois eles são o fundamento sobre o qual a grande superestrutura do conhecimento humano deve ser erguida (REID, 2002, p. 412 , tradução nossa'5).

A título de exemplo, aponto dois ramos do conhecimento que devem ser construídos a partir de princípios primeiros do senso comum:

a) A filosofia da mente, a ciência que investiga os fenômenos mentais (como, por exemplo, o modo como as faculdades operam e a origem das concepções e crenças humanas), é fundada sobre princípios primeiros do senso comum. Para Reid, é preciso assumir, como princípio primeiro na investigação da mente humana que as operações mentais de que estamos conscientes realmente existem. Este princípio primeiro é formulado nos seguintes termos: "Em primeiro lugar, devo assumir como certo que eu 'penso', que eu 'me lembro', que eu 'raciocínio', e, que, em geral, eu realmente executo todas aquelas operações da mente de que estou consciente" (REID, 2002, p. 41, tradução nossa).

A crença na existência das operações e emoções mentais é produzida por uma faculdade em particular da mente, a consciência. É ela quem atesta a existência de tudo o que se passa no interior da mente humana. Por isso, seria

\footnotetext{
15 Do original: I acknowledge, that if we were to rest in those judgments of Nature of which we now speak, without building others upon them, they would not entitle us to the denomination of reasonable beings. But yet they ought not to be despised, for "they are the foundation upon which the grand superstructure of human knowledge must be raised".
} 
impossível empreender a investigação dos fenômenos mentais sem confiar na verdade desta crença devida às operações da faculdade da consciência.

b) A ciência moral, ou 'sistema de moralidade', como Reid a chama (um sistema de princípios que nos auxiliaria na descoberta do certo e do errado na conduta), é fundado por princípios primeiros do senso comum. Para Reid, é preciso assumir como princípio primeiro em um sistema de moralidade que a conduta humana pode ser aprovada e desaprovada do ponto de vista moral. Esse princípio primeiro do senso comum é formulado nos seguintes termos: "Existem algumas coisas na conduta humana que merecem aprovação e louvor e outras que merecem censura e punição, e diferentes graus de aprovação ou culpa são devidos a diferentes ações" (REID, 2010, p. 271, tradução nossa). Esta crença do senso comum assumida como princípio primeiro de um sistema de moralidade é produzida por uma faculdade mental particular, a "consciência moral" ${ }^{16}$. Negar essa crença e, consequentemente, este princípio de um sistema de moralidade, é a impossibilidade de se avaliar qualquer ação em uma perspectiva moral. Como reconhecer a virtude e o vício se não se aceita que algumas ações são dignas de aprovação e outras de reprovação?

Cumpre explicar, ainda que eu não me detenha demoradamente sobre esses pontos, em primeiro lugar, que Reid possui um conjunto de argumentos em favor da verdade dos princípios primeiros do senso comum. Ele não deixa o senso comum injustificado do ponto de vista epistêmico, como pretendem alguns intérpretes, como, por exemplo, Yves Michaud (1989) ${ }^{17}$. Procurei mostrar, em outro trabalho, estes argumentos

\footnotetext{
16 "Alguns filósofos, com quem concordo, atribuem isso [os juízos sobre o certo e o errado na conduta humana] a um poder original ou faculdade no homem que eles chamam 'senso moral', ou 'faculdade moral', ou 'consciência'” (REID, 2010, p. 175, tradução nossa).

17 Yves Michaud sugere que Reid não justifica o senso comum em sua tentativa de responder ao ceticismo de David Hume e outros autores modernos. Afirmar que as crenças do senso comum são naturais não poderia ser entendido como uma justificação para elas, uma vez que seria apenas uma reafirmação delas: "o erro de Reid, mas um erro de qualquer filosofia do senso comum, é negligenciar o elemento cético irresistível que permanece no âmago das próprias crenças naturais: elas são meramente naturais" (MICHAUD, 1989, p. 31, tradução nossa).
} 
que compõem a defesa de Reid do senso comum e seus princípios ${ }^{18}$. Em segundo lugar, embora o uso fundacional do senso comum esteja claro na filosofia de Reid (não existe divergência na literatura secundária sobre o papel fundacional do senso comum no tocante ao conhecimento), do ponto de vista do modo como ocorre esta fundamentação, os intérpretes divergem entre si. Alguns autores sugerem que Reid é fundacionalista, como, por exemplo, Philip de Bary (2002) ${ }^{19}$ e John Greco (2004) ${ }^{20}$. Outros autores sugerem ou afirmam que Reid é um coerentista, como, por exemplo, Benjamin W. Redekop (2002) 21, Michel Malherbe (1991)22, James Van Cleve (2014) ${ }^{23}$ e, principalmente, o filósofo Keith Lehrer, em um trabalho

18 Ver Vinícius França Freitas (2017). A defesa reidiana da verdade das crenças do senso comum é composta por três argumentos: (1) Reid argumenta que é impossível provar a fiabilidade das faculdades da mente e que, por isso mesmo, os filósofos devem iniciar a investigação pela aceitação da verdade das crenças devidas a estas faculdades; (2) Reid argumenta que seria inconsistente escolher uma única faculdade da mente como fonte de crenças verdadeiras. Isto seria arbitrário (pois de que modo poderíamos escolher uma dentre elas se não arbitrariamente?); (3) Reid argumenta que, se as faculdades da mente operam de modo apropriado, ou seja, quando a mente não é afetada por uma doença ou desordem, os filósofos não teriam boas razões para duvidar da fiabilidade destas faculdades e questionar a verdade das crenças a elas devidas (FREITAS, 2017, p. 152-195).

19 Ver BARY., 2002, p. 49-63.

20 Ver GRECO, 2004, p. 148-151.

${ }^{21}$ Redekop não afirma explicitamente que Reid é um coerentista, mas parece o sugerir. Ao discutir a validade dos princípios primeiros, ele afirma: "como podemos estar certos de que eles são corretos? Princípios primeiros válidos são 'consistentes com outros princípios primeiros', não levam a conclusões absurdas” [...] (REDEKOP, 2002, p. 43, grifo e tradução nossos).

22 Malherbe sugere esta interpretação ao afirmar que a justificação do senso comum está na reciprocidade de seus princípios, princípios que possuiriam o papel de pressupostos teóricos da investigação (os princípios primeiros a partir dos quais o estudo será empreendido) e de resultados encontrados ao fim da investigação filosófica (os princípios da natureza humana revelados pelo estudo atento das operações mentais).

23 Van Cleve afirma a existência de uma "rede de autoevidência" [Web of self-evidence] na filosofia reidiana do conhecimento. Ele diz: "digamos que uma crença é epistemicamente anterior a outra (ou que aquelas crenças de uma classe são epistemicamente anteriores àquelas crenças de outra) se essa última deriva sua evidência da evidência da primeira, de tal maneira que a última não poderia ser evidente a menos que a primeira já o fosse. Digamos que a crença é autoevidente se ela for evidente, mas não há nada epistemicamente anterior a ela. Poderíamos então dizer que a uma teoria da coerência que rejeita a própria ideia de prioridade epistêmica é uma teoria que, ao invés de repudiar a categoria da autoevidência, faz com que cada crença evidente seja autoevidente. Reid, ainda que não vá tão longe, poderia assumir que as crenças particulares e as crenças gerais dependem umas das outras para sua evidência sem com que as crenças, seja de qual tipo for, sejam anteriores umas às outras, de modo que particulares e gerais seriam ambas autoevidentes" (VAN CLEVE, 2014, p. 170, tradução nossa). 
publicado conjuntamente com John-Cristian Smith (1985). Há também a interpretação de Gregory Poore (2015) ${ }^{24}$, para quem existiria uma mistura de fundacionalismo e coerentismo no pensamento reidiano. Procurei argumentar, em outro trabalho, as razões que me levam a defender que Reid é fundacionalista e os motivos que me levam a questionar as interpretações coerentista e fundacionalista/coerentista ${ }^{25}$.

\section{0 uso metodológico do senso comum}

Reid atribui ao senso comum um segundo papel no âmbito filosófico, como fonte de pressupostos metodológicos de investigação. Apresento, na sequência, como o senso comum fornece, segundo o filósofo, (a) o método de investigação filosófica e também (b) certos princípios (metodológicos) sem os quais a investigação filosófica não poderia ser realizada.

a) Para Reid, o método a ser seguido em investigações filosóficas é o "método experimental de raciocínio". Como ele afirma: "[...] o verdadeiro método de filosofar é o seguinte: a partir de causas reais determinadas pela observação e experiência, coletamos as leis da natureza por uma indução exata e as aplicamos para explicar os fenômenos da natureza" (REID, 2002, p. 121, tradução nossa ${ }^{26}$ ). Importa notar, no presente caso, que, ao ver do filósofo, esse método é devido ao senso comum dos seres humanos, à constituição original da mente. Para Reid, "este procedimento do entendimento é familiar a todas as criaturas humanas nos interesses comuns da vida [...]" (REID, 1997, p. 11, tradução nossa ${ }^{27}$ ). Procedendo por

\footnotetext{
24 Poore afirma: "argumento que a epistemologia de Reid não é simplesmente fundacionalista, ela contém traços de coerentismo: [...] ainda que esta justificação impulsionada [boosted justification] não seja, em geral, necessária para o conhecimento, ela é valorosa" (POORE, 2015, p. 213, tradução nossa).

25 Ver Freitas, 2017, p. 22-45.

${ }^{26}$ Do original: The true method of philosophising is this: From real facts ascertained by observation and experiment, to collect by just induction the laws of Nature, and to apply the laws so discovered, to account for the phaenomena of Nature.

${ }^{27}$ Do original: "This procedure of the understanding is familiar to every human creature in the common affairs of life, [...]".
} 
observação e experimentação de fatos cotidianos, os seres humanos descobriram que o frio congela a água; por observação e experimentação, os seres humanos descobriram que o calor a evapora. Tanto nos afazeres da vida comum quanto no caso das descobertas científicas, os seres humanos procederam segundo princípios do senso comum. Por exemplo, Newton, ao seguir o método experimental de raciocínio, procedeu segundo princípios da constituição original da mente: "suas regulae philosophandi são máximas do senso comum, praticadas diariamente na vida comum, de modo que aquele que faz filosofia por meio de outras regras, seja na investigação do sistema material, seja na investigação da mente, erra seu alvo" (REID, 1997, p. 12, tradução nossa ${ }^{28}$ ). Esta é uma inclinação original da mente humana que faz com os seres humanos partam da observação de fatos particulares e cheguem a uma crença sobre este fenômeno. Na vida comum, sabemos que a água congela ou evapora a determinada temperatura; na ciência, sabemos com mais precisão que água congela a $0^{\circ} \mathrm{C}$ e evapora a $100^{\circ} \mathrm{C}$.

b) Além do método de investigação, o senso comum oferece certos princípios que podem ser entendidos como princípios metodológicos em certos campos do saber. No presente caso, cito os casos da filosofia da natureza e da política. Ambas as ciências dependem metodologicamente de princípios sobre regularidades: a regularidade nos fenômenos naturais e a regularidade do comportamento humano. Para Reid, ambas as crenças (na regularidade da natureza e na regularidade do comportamento humano) são devidas aos princípios da constituição original da mente, o senso comum. Por um lado, a mente humana é formada de modo a supor inevitavelmente a uniformidade na natureza:

Somos feitos de tal forma que, quando duas coisas se encontram conjugadas em certas circunstâncias, estamos propensos a acreditar que elas estão conectadas na natureza

28 Do original: His 'regulae philosophandi' are maxims of common sense, and are practised every day in common life; and he who philosophizes by other rules, either concerning the material system, or concerning the mind, mistakes his aim 
e sempre serão encontradas juntas em circunstâncias semeIhantes. A crença a que somos levados em tais casos não é efeito do raciocínio, nem surge da evidência intuitiva na coisa em que se crê. Ela é, como a apreendo, o efeito imediato de nossa constituição (REID, 2002, p. 238, tradução nossa ${ }^{29}$ ).

Reid formula a proposição que expressa esta crença nos seguintes termos: “[...] nos fenômenos da natureza, o que é provavelmente será semelhante ao que foi em circunstâncias similares" (REID, 2002, p. 489, tradução nossa ${ }^{30}$ ). Por outro lado, a mente humana é formada de modo a supor inevitavelmente a uniformidade do comportamento humano:

Pode haver em alguns indivíduos tal grau de frenesi e loucura que nenhum homem pode dizer o que eles podem ou não fazer. Consideramos necessário colocar tais pessoas sob restrição, tanto quanto for possível evitar que elas causem danos a elas mesmas ou a outras. Elas não são consideradas criaturas sensatas ou membros da sociedade. Contudo, quanto aos homens de mente saudável, dependemos de certo grau de regularidade em suas condutas. Colocados em mil casos diferentes, poderíamos arriscar, dez para um, que eles agiriam de tal maneira e não de maneira contrária (REID, 2002, p. 488, tradução nossa31).

\footnotetext{
29 Do original: We are so made, that when two things are found to be conjoined in certain circumstances, we are prone to believe that they are connected by nature, and will always to believe that they are connected by nature, and will always be found together in like circumstances. The belief which we are led into in such cases is not the effect of reasoning, nor does it arise from intuitive evidence in the thing believed; it is, as I apprehend, immediate effect of our constitution: [...].

30 Do original: That, in the phenomena of nature, what is to be, will probably be like to what has been in similar circumstances.

31 Do original: There may be in some individuals such a degree of phrenzy and madnress, that no man can say what they may or may not do. Such persons we find it necessary to put under restraint, that as far as possible they may be kept from doing harm to themselves or to others, They are not considered as reasonable creatures, or members of society. But, as to men who have a sound mind, we depend upon a certain degree of regularity in their conduct; and could put a thousand different cases, wherein we could venture, ten to one, that they will act in such a way, and not in the contrary.
} 
Reid formula a proposição que expressa esta crença nos seguintes termos: "Existem muitos eventos dependentes da vontade do homem nos quais há uma probabilidade autoevidente, maior ou menor, de acordo com as circunstâncias" (REID, 2002, p. 488, tradução nossa). A filosofia da natureza não poderia existir sem se apoiar sobre esse princípio metodológico. De que modo Newton poderia ter descoberto o "princípio da inércia" sem pressupor a uniformidade dos fenômenos naturais? Do mesmo modo, a ciência política, tal qual Reid a entende ${ }^{32}$, não poderia existir sem o princípio metodológico sobre a uniformidade do comportamento humano.

\section{0 uso instrumental do senso comum}

Além dos usos fundacional e metodológico, o senso comum possui um terceiro papel na filosofia de Reid, o de "instrumento de refutação" de princípios e conclusões filosóficas. De acordo com Reid, uma conclusão que contradiz o senso comum possui uma das mais claras marcas da falsidade:

Ademais, tenho de observar apenas que o domínio do senso comum é mais extenso na refutação do que na confirmação. Uma conclusão extraída de princípios verdadeiros por uma corrente de raciocínio justo não pode contradizer possivelmente nenhuma decisão de senso comum, porque a verdade sempre será consistente com ela mesma. Tampouco tal conclusão recebe alguma confirmação do senso comum, porque não está em sua jurisdição (REID, 2002, p. 433, tradução nossa ${ }^{33}$ ).

32 Do ponto de vista da ciência, a política é uma teoria sobre as ações humanas, sobre as ações de um corpo de indivíduos: "o seu propósito é mostrar como um corpo de homens agirá nas diversas situações nas quais eles são colocados, de que modo eles podem ser colocados em tais situações, assim como levá-los, ou a maior parte deles, a desempenhar o papel que é esperado que eles desempenhem" (REID, 2015, p. 32, tradução nossa).

33 Do original: I have only this farther to observe, that the province of common sense is more extensive in refutation than in confirmation. A conclusion drawn by a train of just reasoning from true principles cannot possibly contradict any decision of common sense, because truth will always be consistent with itself. Neither can such a conclusion receive any confirmation from common sense, because it is not within its jurisdiction. 
Enquanto em seu uso fundacional, o senso comum oferece crenças que são assumidas como fundamento de conhecimento - por exemplo, a crença de que as operações e emoções da mente existem; enquanto em seu uso metodológico, o senso comum oferece certos pressupostos metodológicos para a investigação filosófica - como, por exemplo, o método de extrair uma conclusão geral a partir da observação e experimentação de casos particulares; Em seu uso instrumental, diferentemente dos usos fundacional e metodológico, o senso comum funciona como uma barreira que impediria que o filósofo assuma determinados princípios e conclusões como verdadeiras. Nessa forma particular de uso, o senso comum não é construtivo, não oferece princípios de conhecimento, tampouco pressupostos epistemológicos, mas destrutivo: alerta ao filósofo sobre a possibilidade de ele estar assumindo crenças falsas ${ }^{34}$.

Um princípio ou conclusão que contradiz o senso comum possui uma das marcas da falsidade, ele é absurdo e, por isso, desperta na mente uma emoção particular. De acordo com Reid, há um princípio original da mente que faz com que nos sintamos 'ridículos' diante de opiniões absurdas: "para desaprovar o absurdo, a natureza nos deu uma emoção particular, a saber, aquela do ridículo, que parece destinada para este fim: não permitir a aprovação do que é absurdo, seja na opinião ou na prática" (REID, 2002, p. 462, tradução nossa35). A história da filosofia, segundo Reid, mostra muitas destas opiniões que, por entrarem em conflito com o senso comum, produzem esta emoção do ridículo:

Zenão esforçou-se por demonstrar a impossibilidade do movimento; Hobbes, que não há diferença entre o certo e o errado; e este autor [Hume], que nenhum crédito deve ser dado aos

\footnotetext{
34 Gostaria de manifestar aqui meus agradecimentos ao avaliador do artigo pela sugestão de esclarecer a diferença entre os usos fundacional e instrumental do senso comum.

35 Do original: And, to discountenance absurdity, Nature hath given us a particular emotion, to wit, that of ridicule, which seems intended for this very purpose of putting out of countenance what is absurd, either in opinion or practice.
} 
nossos sentidos, à nossa memória, ou mesmo às demonstrações. Tal filosofia é, com justiça, ridícula, mesmo para aqueles que não detectam sua falácia (REID, 1997, p. 21, tradução nossa ${ }^{36}$ ).

Mesmo aqueles que não são versados em filosofia, incapazes de raciocinar rigorosamente em busca dos erros que levam a essas conclusões, são capazes de reconhecer a falsidade dessas opiniões. Todos nós, filósofos ou não, sentimo-nos ridículos diante de tais opiniões. Deste modo, o senso comum, por meio da emoção do ridículo, impede-nos de aceitar certos princípios ou conclusões absurdas ${ }^{37}$.

Discuto dois pontos acerca desse uso instrumental do senso comum, como ponto de apoio de princípios e conclusões, no pensamento de Reid:

a) Segundo Laurent Jaffro (2006), a "forma extrema" que uma filosofia do senso comum pode assumir é aquela que rejeita toda e qualquer teoria cujos princípios ou conclusões contradigam o senso comum. Nesse sentido, uma filosofia extrema do senso comum seria apenas

36 Do original: Zeno endeavoured to demonstrate the impossibility of motion; Hobbes, that there was no difference between right and wrong; and this author, that no credit is to be given to our senses, to our memory, or even to demonstration. Such philosophy is justly ridiculous, even to those who cannot detect the fallacy of it.

37 O uso instrumental do senso comum, como ponto de apoio para refutações, não é uma novidade na história da filosofia. François Fénelon (1651-1715), por exemplo, refere-se a ele em Demonstration de l'Existence de Dieu (1718). Fénelon explica a origem da emoção do ridículo diante de certas opiniões. $O$ exemplo pensado por ele diz respeito à pergunta sobre a possibilidade de o "nada" ser capaz de pensar. Diante desta pergunta, os seres humanos estariam mais inclinados ao riso do que a uma investigação séria: "em que consiste o ridículo destas [questões]? A que podemos atribuir isso precisamente? Ao choque do senso comum, alguém poderá dizer. Mas o que é este senso comum? Não é ele as primeiras noções que todos os homens têm das mesmas coisas? Este senso comum que é o mesmo em todos os lugares; que previne exames; que faz um homem rir ao invés de investigar; que reduz um homem àquele passo em que ele não pode duvidar, ainda que ele se esforce sinceramente por colocar-se em uma dúvida verdadeira. Este senso comum que é o de todos os homens, este senso que espera apenas para ser consultado, que se manifesta ao primeiro olhar e descobre imediatamente a perspicácia ou a absurdidade da questão" (FÉNELON, 1721, p. 196, tradução nossa). Para Fénelon, as opiniões que chocam o senso comum têm a capacidade de despertar o riso naqueles que as ouvem. Reid parece ter aprendido essa lição do próprio filósofo francês. Ele não apenas cita na íntegra esta explicação de Fénelon da origem da emoção do ridículo como acrescenta: "devo apenas observar, sobre esta passagem, que a interpretação que ela dá ao critério de verdade de Descartes, justa ou não, é a mais inteligível e a mais favorável com a qual entrei em contato" (REID, 2002, p. 430-431, tradução nossa). 
"reativa", uma filosofia que principalmente refuta princípios e conclusões filosóficas ${ }^{38}$. De fato, encontramos esse uso instrumental na filosofia de Reid. Contudo, acredito que, a partir do que foi dito ao longo do artigo, a filosofia reidiana não pode ser entendida como uma forma extrema de filosofia do senso comum. O senso comum, em Reid, é o fundamento do conhecimento humano. O edifício do conhecimento humano se assenta todo sobre seus princípios primeiros. O senso comum também oferece o método de investigação, o método experimental, e certos princípios metodológicos, como, por exemplo, os princípios sobre a regularidade dos fenômenos naturais e das ações humanas. Esses usos dizem respeito ao aspecto construtivo da filosofia de Reid: a busca pela verdade e a garantia do conhecimento. O uso instrumental, por outro lado, está relacionado ao aspecto desconstrutivo da filosofia reidiana, o questionamento de outros sistemas de filosofia, em especial, aqueles que contradizem o senso comum.

b) Daniel Schulthess (1983) nota o que, a seu ver, é uma das dificuldades do uso que Reid faz da emoção do ridículo no âmbito filosófico: ter colocado uma emoção na mesma categoria de opiniões falsas (1983, p. 91-94). Como um fato puramente psicológico, uma emoção, pode dizer algo sobre a verdade ou falsidade de uma opinião, isto é, um fato epistemológico? Em resposta à perplexidade do intérprete, eu diria que Reid não coloca uma emoção e uma crença - estados psicológicos claramente distintos - em uma mesma categoria. O que Reid faz é alertar que certa emoção da mente é capaz de impedir que o ser humano dê seu assentimento a uma crença e a assuma como crença verdadeira. Como o indivíduo poderia aceitar como verdadeira uma crença que o faz rir? É neste sentido que Reid afirma que a emoção do ridículo tem uma significância epistêmica. Uma opinião não é falsa porque contradiz o senso comum.

\footnotetext{
38 Jaffro diz: "qual é a principal tese de uma filosofia do senso comum? Sob sua 'forma extrema', ela afirma que uma teoria que mantém princípios ou extrai consequências que são contrárias às crenças ordinárias e comuns deve ser rejeitada como falsa. Uma filosofia do senso comum assim definida é essencialmente reativa - ela refuta filosofias mostrando que elas são contrárias ao senso comum" (JAFFRO, 2006, p. 19, grifo e tradução nossas).
} 
Uma opinião não é falsa porque faz despertar a emoção do ridículo na mente humana. A emoção apenas impediria o assentimento a uma crença e faria com que fosse necessário um exame mais aprofundado da mesma antes que ela pudesse ser aceita como verdadeira ${ }^{39}$.

Isso fica mais claro ao se considerar o caso da crítica de Reid empreendida à teoria das ideias ${ }^{40}$ e ao princípio ideal, a hipótese de que as ideias são os únicos objetos imediatos das operações da mente ${ }^{41}$. Reid, com efeito, afirma: “a 'primeira' reflexão que faria sobre esta opinião filosófica é que ela é diretamente contrária ao senso universal dos homens que não foram instruídos em filosofia" (REID, 2002, p. 172, tradução nossa42). Os seres humanos ao verem o sol ou a lua não duvidam de que estes objetos que veem imediatamente são o próprio sol e a própria lua. Contudo,

Ficamos muito abismados quando os filósofos nos informam que estamos errados em tudo isso: que o sol e a lua que vemos não estão, como imaginamos, a milhas de distância de nós e um do outro, mas que estão em nossas próprias mentes; que eles não têm existência antes de os vermos e que eles não existirão quando deixarmos de pensar ou percebê-los; porque os objetos que percebemos são apenas ideias em nossas mentes

39 Gostaria de manifestar aqui meus agradecimentos ao avaliador do artigo pelos comentários e sugestões acerca deste uso instrumental do senso comum e o modo como uma emoção pode ter alguma orientação para a verdade.

40 Esta passagem resume a compreensão de Reid do sistema ideal: "os filósofos, com efeito, dizem-me que o objeto imediato da memória e, neste caso, da imaginação, não é uma sensação passada, mas uma ideia desta sensação, uma 'imagem', um 'fantasma', ou uma espécie do odor que cheirei. Dizem que esta ideia existe agora em minha mente, ou no sensório, que a mente contempla esta ideia presente, encontrando nela uma 'representação' do que é passado ou do que pode existir, chamando-a memória ou imaginação. Esta é a doutrina da filosofia ideal" (REID, 1997, p. 28, tradução nossa).

${ }_{41}$ Esta passagem resume a compreensão de Reid do princípio ideal que ele combate: "para evitar erros, o leitor deve também ser lembrado que se ideias significam apenas os atos ou operações de nossas mentes ao perceber, lembrar ou imaginar os objetos, estou longe de colocar em questão a existência destes objetos. [...] As ideias de cuja existência exijo provas não são as operações de uma mente, mas os supostos objetos destas operações. Elas não são percepção, lembrança, ou concepção, mas coisas que são ditas como percebidas, lembradas ou imaginadas" (REID, 2002, p. 171, tradução nossa).

42 Do original: The first reflection I would make on this philosophical opinion is, That is directly contrary to the universal sense of men who have not been instructed in philosphy. 
que não podem existir um momento mais para além daquele em que neles pensamos (REID, 2002, p. 172, tradução nossa ${ }^{43}$ ).

Reid continua: "para o não instruído em filosofia, deve parecer extravagante e visionário e o mais contrário aos ditados do entendimento comum" (REID, 2002, p. 173, tradução nossa). A opinião de que não percebemos os objetos externos, mas as imagens desses, as ideias, é absurda, choca o senso comum. No entanto, Reid não se detém sobre essa única reflexão ao considerar o princípio da teoria das ideias. Com efeito, ele apresenta outras quatro reflexões: os autores da teoria das ideias nunca provaram a existência das ideias (segunda reflexão); os autores da teoria das ideias, apesar de suporem a existência das ideias, dificilmente concordam em algum ponto referente às ideias (terceira reflexão); a pressuposição de ideias não torna a explicação do funcionamento das operações da mente mais fácil (quarta reflexão); e, por fim, as conclusões extraídas a partir da hipótese da existência das ideias são paradoxais (quinta reflexão) (REID, 2002, p. 171-187). Tal como Reid entende, a opinião de que o mundo externo de objetos físicos não existe (REID, 2002, p. 137-161) ou a opinião de que não temos razões seguras que nos permitam supor a existência destes objetos (REID, 2002, p. 161-165) não são falsas porque contradizem o senso comum da humanidade. Elas não são falsas porque despertam na mente a emoção do ridículo. O ser humano, diante de tais opiniões, sente-se inclinado ao riso, incapazes de aceitá-las como verdadeiras. Um exame mais aprofundado revela que são falsas porque decorrem de um princípio falso, o princípio de que a mente não entra em contato com os objetos do mundo, mas com ideias desses objetos. O uso instrumental, a meu ver, chama a atenção para uma opinião que precisa ser filosoficamente avaliada.

\footnotetext{
43 Do original: But how are we astonished when the Philosopher informs us, that we are mistaken in all this; that the sun and moon which we see, are not, as we imagine, many miles distant from us, and from each other, but that they are in our own mind; that they had no existence before we say them, and will have have none when we cease to perceive and to think of them; because the objects we perceive are only ideas in our own minds, which can have no existence a moment longer than we think of them.
} 


\section{Considerações finais}

Este artigo lidou com a questão da relação entre a filosofia de Reid e o senso comum. Mais especificamente, ele procurou explicar os usos do senso comum no pensamento reidiano. Tal como o entendo, Reid ensina que, no âmbito da investigação filosófica, é possível recorrer à constituição original da mente humana, o senso comum, de - ao menos - três formas diferentes. Primeiramente, o senso comum pode oferecer um ponto de apoio seguro - ainda que eu não tenha me detido, neste artigo, sobre a questão do modo como Reid defende o senso comum como fundamento do conhecimento - sobre o qual podemos edificar o conhecimento humano. Ele fornece-nos as crenças que devemos assumir como os princípios primeiros do conhecimento humano em diferentes campos de investigação, como, por exemplo, a filosofia da mente e a ciência moral. Além desse uso fundacional, Reid apela ao senso comum no que diz respeito ao método de investigação filosófica: o senso comum fornece certos pressupostos metodológicos sem os quais a investigação filosófica não poderia ser empreendida. Para Reid, o próprio método experimental de raciocínio seguido por Newton é devido à constituição original da mente humana, o senso comum. Ademais, crenças acerca da uniformidade da natureza e acerca da uniformidade do comportamento humano em geral, necessárias ao filósofo que pretende investigar os fenômenos naturais e políticos, têm sua origem na própria natureza humana. Por fim, Reid usa senso comum como instrumento de refutação de princípios e conclusões filosóficas. De que maneira? Uma opinião que contradiz o senso comum é absurda e desperta na mente humana uma certa emoção: sentimo-nos ridículos diante de certos princípios ou conclusões filosóficas. Essa emoção não é uma prova de que essas opiniões são falsas, contudo, sentirmo-nos ridículos diante delas é um sinal de que devemos analisá-las mais detidamente em busca de sua verdade.

\section{Referências}


BARY, P. Thomas Reid and scepticism: his reliabilist response. London: Routledge, 2002. https://doi.org/10.4324/9780203166208

BEANBLOSSOM, R. E. Introduction. In: BEANBLOSSOM, R. E.; LEHRER, K. (ed.). Thomas Reid's inquiry and essays. Indianapolis: Hackett, 1983.

CLEVE, J. Lehrer, Reid, and the first of all principles. In: OLSSON, E. J. (ed.). The epistemology of Keith Lehrer. New York: Springer, 2003. p. 155-172. https:// doi.org/10.1007/978-94-010-0013-0_11

FÉNELON, F. Oeuvres philosophiques, ou demonstration de l'existence de Dieu. Amsterdam: L'Honore et Chatelain, 1721.

FREITAS, V. F. Thomas Reid on the First principles of speculative, moral and political knowledge. Tese (Doutorado em Filosofia) - Faculdade de Filosofia e Ciências Humanas, Universidade Federal de Minas Gerais, Belo Horizonte, 2017. https://doi.org/10.24873/j.rpemd.2017.07.018

GRECO, J. Reid's reply to the skeptic. In: CUNEO, T.; WOUNDENBERG, R. (ed.). The Cambridge Companion to Thomas Reid. Cambridge: Cambridge University, 2004. p. 134-155. https://doi.org/10.1017/ccol0521812704.006

JAFFRO, L. Les recours philosophique au sens commun dans les lumières britanniques. In: SYLVESTRE, J. P. ; GUENANCIA, P. (ed.). Le sens commun. Dijon: Editions Universitaires de Dijon, 2006. p. 19-45. https://doi.org/10.1017/ s0395264900035897

KANT, I. Prolegómenos a toda a metafísica futura. Tradução de Artur Morão. Lisboa: Edições 70, 1988.

LEHRER, K.; SMITH, J-C. Reid on testimony and perception. Canadian Journal of Philosophy, Edmonton, v. 15, suppl. 1, p. 21-38, 1985. https://doi.org/10.10 80/00455091.1985.10715888

MALHERBE, M. Reid et la possibilité d'une philosophie du sens commun. Revue de Métaphysique et de Morale, Paris, v. 96, n. 4, p. 551-571, 1991. https://doi. org/10.3917/rmm.063.0385

MARCIL-LACOSTE, L. Claude Buffier and Thomas Reid: two common-sense philosophers. Kingston: McGill-Queen's University, 1982. https://doi. org/10.1017/so012217300045236

MICHAUD, Y. Reid's attack on the theory of ideas:: from a reconsideration of Reid's arguments to a reassessment of the theory of ideas. In: DALGARNO, M.; MATTHEWS, E. (ed.). The philosophy of Thomas Reid. Dordrecht: Kluwer Academic, 1989. p. 9-34. https://doi.org/10.1007/978-94-009-2338-6_3 
POORE, G. Theism, coherence, and justification. In: COPENHAVER, R.; BURAS, T. (ed.). Thomas Reid on mind, knowledge, and value. Oxford: Oxford University, 2015. p. 213-231.

https://doi.org/10.1093/acprof:oso/9780198733676.003.0012

REDEKOP, B. W. Thomas Reid and the problem of induction: from common experience to common sense. Studies in History and Philosophy of Science: part A, Elmsford, v. 33, n. 1, p. 35-57, 2002. https://doi.org/10.1016/ s0039-3681(01)00022-X

REID, T. Essays on the active powers of man. Edinburgh: Edinburgh University, 2010.

REID, T. Essays on the intellectual powers of man. Edinburgh: Edinburgh University, 2002.

REID, T. Inquiry into the human mind on the principles of common sense. Edinburgh: Edinburgh University, 1997.

REID, T. Thomas Reid on politics and society. Edinburgh: Edinburgh University, 2015. https://doi.org/10.1093/oseo/instance.00174897

SCHULTHESS, D. Philosophie et sens commun chez Thomas Reid (1710-1796). Berne: Editions P. Lang, 1983.

SOMMERVILE, J. Reid's conception of common sense. The Monist, La Salle, v. 70, n. 4, p. 418-429, 1987. https://doi.org/10.5840/monist198770424

WOLTERSTORFF, N. Thomas Reid and the story of epistemology. New York, Cambridge University, 2001. https://doi.org/10.1017/CBO9780511613845

\section{Endereço postal}

\section{Vinícius França Freitas}

Rua Trinta e um de março, n. 64, Apartamento 202.

CEP. 38702-002,

Patos de Minas-MG 